\title{
GEOLOGIA DE LAS MARGENES DE LA PLACA DEL CARIBE: GENERALIDADES EN GUATEMALA, COSTA RICA, LA ESPAÑOLA Y RESULTADOS PRELIMINARES DEL ANALISIS DE UNA TRANSVERSAL EN LA CORDILLERA DE LA COSTA DE VENEZUELA
}

\author{
Giunta, G. ${ }^{1}$, Navarro, E. ${ }^{2}$, Beccaluva, L. ${ }^{3}$, Bellia, S. ${ }^{4}$, Comin-Chiaramonti, P. ${ }^{4}$, \\ Dengo, G. ${ }^{5}$, Montero, W. ${ }^{6}$, Urbani, F. ${ }^{2}$, Carnemolla, S. ${ }^{1}$ \\ ${ }^{1}$ Dept. Geología - Universidad de Palermo, Italia \\ ${ }^{2}$ Escuela de Geología - Universidad Central de Venezuela, Caracas \\ ${ }^{3}$ Instituto de Mineralogía - Universidad de Ferrara, Italia \\ ${ }^{4}$ Instituto de Mineralogía - Universidad de Palermo, Italia \\ ${ }^{5}$ Centro de Estudios Geológicos de América Central e ICAITI, Guatemala \\ ${ }^{6}$ Escuela Centroamericana de Geología, Universidad Costa Rica, San José
}

\begin{abstract}
The Caribbean Plate margins are constituted by deformed belts built up since the Cretaceous in a compressional and strike-slip stress field, which allowed overthrusting of the Caribbean crust onto the Pacific, North and South American Plates.

The Caribbean borders include Jurassic-Cretaceous ophiolitic units (Great Antilles, Venezuela, Costa Rica, Guatemala, etc.), composed by mantle peridotites, gabbros, volcanic and sedimentary covers, which have been deformed in at least two ductile penetrative phases and were often metamorphosed in the prehnite-pumpelleyite, green and blue schist, amphibolite, and in places eclogite facies. These units may present part of a subduction complex or are an accretionary prism.

This paper deals with a regional geological survey (1989-1993) conducted on the main periCaribbean ophiolitic units of Guatemala, Costa Rica, Hispanola, and Venezuela. The preliminary data, recently updated with new and detailed researches, allow to recognize the magmatic affinities (MORB and IAT) of the different reconstructed lithological sequences, which can be related with an hypothetical kinematic model of the development of the Caribbean Plate.
\end{abstract}

RESUMEN: Los márgenes de la placa del Caribe están constituidos por cinturones deformados debido a una serie de fases compresivas ocurridas desde el Cretácico, con esfuerzos tensionales y/o fallas transcurrentes superpuestos. Estos cinturones deformados contienen porciones variables de corteza caribeña sobrecorrida a las placas adyacentes (Norte y Suramericana, Pacífica).

En las Antillas Mayores, Venezuela, Costa Rica y Guatemala se conocen unidades ofiolíticas de edad JurásicaCretácica, constituidas por secuencias de manto, corteza y una cubierta sedimentaria más o menos espesa; las secuencias se encuentran generalmente serpentinizadas, deformadas en al menos dos fases dúctiles penetrativas y metamorfizadas en las facies prehnita-pumpellita, esquistos azules y esquistos verdes.

Desde el punto de vista tectónico-cinemático es posible incluir estas unidades en porciones de complejos de subducción construidos por accreción o "underplating".

En el presente estudio regional sobre las principales unidades ofiolíticas de los márgenes del Caribe, se evidencian diferentes secuencias litológicas pertenecientes a procesos evolutivos con diferentes tendencias, desde MORB a IAT.

Los resultados preliminares de una transversal en la Cordillera de la Costa de Venezuela permiten interpretar algunas secuencias litológicas como provenientes de protolitos tipo MORB. 


\section{ANTECEDENTES}

En los últimos años ha crecido el interés por estudios geológicos del área del Caribe y América Central. Los problemas relacionados con la evolución de la placa del Caribe no se pueden separar de la influencia de las grandes placas de Norte y Sur América.

En las publicaciones sobre la región del Caribe, no se encuentran muchos trabajos de síntesis si bien una amplia bibliografía está contenida en Mascle et al. (1985) y Dengo et al. (1990), de los cuales se puede partir para tener un conocimiento regional aproximado sobre esta área. De un análisis de la geología centroamericana basado en el estudio de la literatura y un reconocimiento preliminar de campo emergen algunos problemas de vital importancia, como son: a) Entender la geofísica de la corteza de cada sector con un consecuente modelo relativo a la característica de la corteza; b) El carácter petrológicogeoquímico del magmatismo producido desde el Mesozoico hasta el presente, tanto en los márgenes como en el interior de la placa del Caribe; c) La arquitectura de los márgenes de la placa y la geometría de los sectores clave; d) La evolución cinemática de la placa del Caribe que sea compatible con los sistemas adyacentes (Pacífico, Norte y Sur América).

Desde hace algún tiempo opera un grupo de investigación bilateral italo-latinoamericano, con el objetivo de estudiar algunas particularidades de los márgenes deformados de la placa del Caribe donde afloran unidades tectónicas de tipo ofiolítico. De hecho, a lo largo de los márgenes, se encuentran de manera más o menos extensa, unidades de manto, corteza y a veces cobertura sedimentaria generalmente atribuidas a "ofiolitas" jurásico-cretácicas. Estas unidades están a menudo asociadas a intrusiones y flujos de lava de tipo calcoalcalino de edad Cretácico Tardío a Cenozoico.

Las características del magmatismo "ofiolítico", partiendo de trabajos de síntesis (e.g.: Donnelly et al. 1990), es aún objeto de discusión y controversia. En las diferentes unidades consideradas, se observan variaciones en las características del metamorfismo y de la tendencia evolutiva del magmatismo. Se presentan ofiolitas del tipo MORB, con afinidad IAT ("island arc tholeiites) y tendencia evolutiva hacia PIA ("primitive island arc"). Una parte de los cinturones ofiolíticos considerados, podrían haber constituido la terminación occidental de la Tethys durante el Jurásico-Cretácico (Auboin et al., 1977; Auboin \& Tardy, 1980).

El presente trabajo presenta el estado de nuestra investigación, incluyendo en ella la problemática regional y los resultados preliminares obtenidos en zonas definidas, que han sido seleccionadas después del análisis de la bibliografía existente y consideradas como las más representativas, después de una etapa de reconocimiento.

\section{LA PLACA DEL CARIBE: Generalidades}

La placa del Caribe, desde el punto de vista geodinámico, es el resultado de la interacción de las placas limítrofes Nazca, Cocos, Norte y Sur America, desde el Mesozoico hasta el presente (Fig. 1). Su evolución, asociada a un proceso cinemático continuo está condicionada a la historia del océano Atlántico desde el Mesozoico, a partir de la nucleación de elementos conectados a él, hasta su individualización como unidad litosférica independiente.

Los actuales vectores de movimiento son consecuencia de la posición de "cojinete" de la misma, entre las placas Norteamericana y Suramericana desplazándose con dirección oeste la primera y noroeste la segunda (e.g.: McDonald, 1990).

Como primera aproximación, la placa del Caribe está constituida de una porción central poco deformada (Cuencas de Colombia y Venezuela), limitada por dos parejas de sistemas activos: septentrional y meridional que constituyen zonas de cizalle más o menos discretas de tipo transcompresivo o solo transcurrente (Motagua, Cayman, Grandes Antillas; Andes septentrionales, Oca, San Sebastián, El Pilar). Los márgenes al oeste y al este están constituidas por sistemas colisionales con subducción tipo $\mathrm{B}$, que desarrollan sobre el margen en obducción, arcos insulares más o menos evolucionados (Istmo Centroamericano y Antillas Menores).

Los modelos más representativos de la corteza (e.g.: Case et al., 1990) prevén características oceánicas y transicionales para la corteza de las cuencas de Colombia y Venezuela y de transicionales a continentales para la corteza del margen de la placa (aparte de la dispersión oceánica presente en el sistema de Cayman). En el límite actual de la placa se involucran, a veces, amplios 


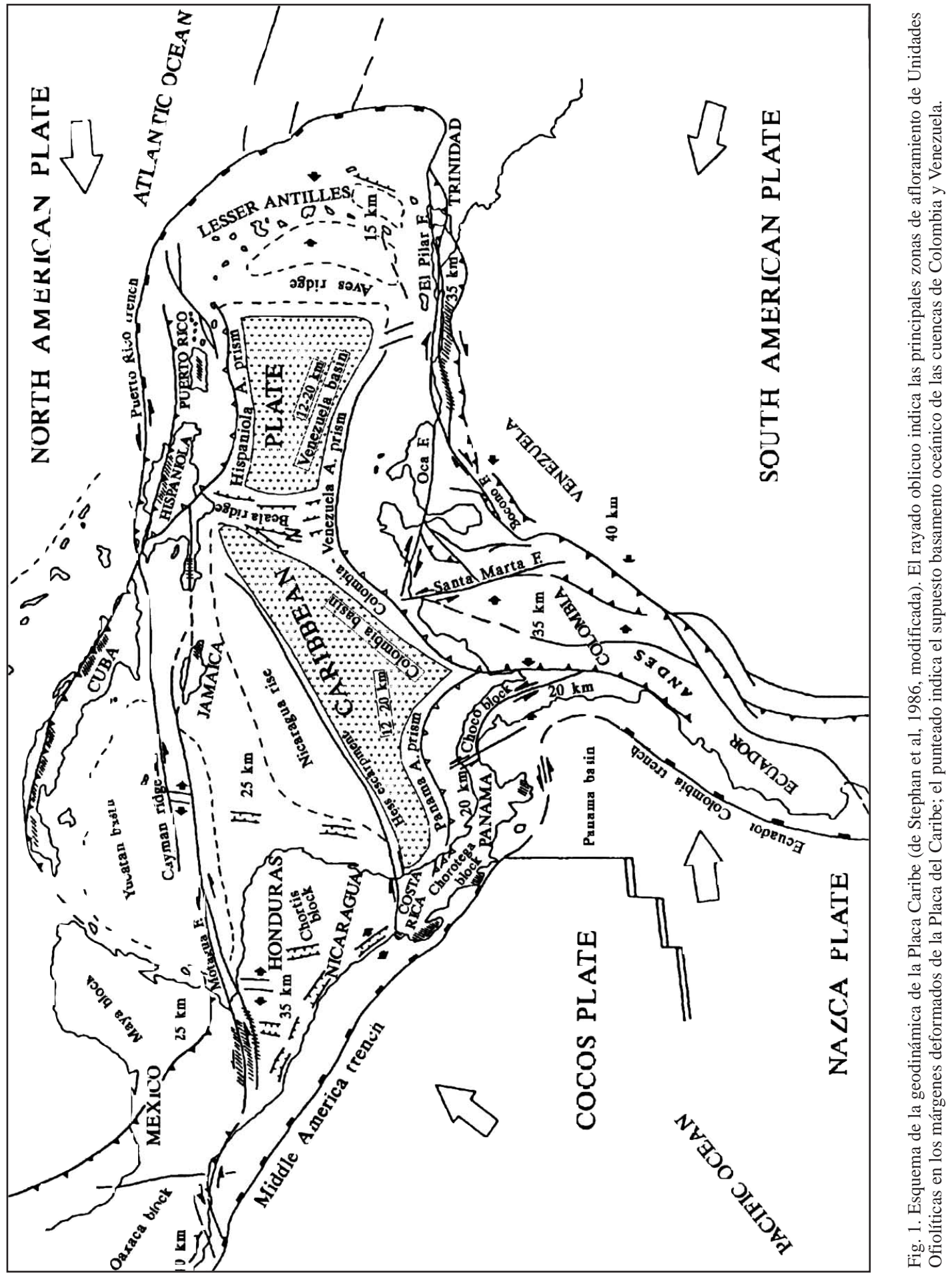


sectores de corteza continental antigua en origen pertenecientes a las placas norte o suramericana.

Los márgenes de la placa del Caribe están compuestos por cinturones deformados por efecto de una serie de fases compresionales a veces sobreimpuestas por fases tensionales y/o transcurrentes, a partir del Cretácico. Tales cinturones abarcan porciones extensas de la placa y de las áreas adyacentes. Específicamente la corteza caribeña está deformada y apilada sobre las cortezas oceánicas pacífica y atlántica (con formación de los arcos insulares variadamente evolucionados que constituyen los márgenes occidental y oriental), y sobre la corteza continental norte y suramericana (con desarrollo de suturas en sistemas cordilleranos complejos en los márgenes septentrional y meridional). Además, la corteza caribeña está frecuentemente deformada en su interior abarcando sectores originalmente estables, en una serie de prismas de acreción (Venezuela, Colombia, Panamá, Española, etc.) definidos como "pseudosubduciones" inducidas por las colisiones principales a lo largo de los márgenes (Stephan et al., 1986).

En general, es posible esquematizar a cada uno de los márgenes del Caribe como estructuras en flor ("flower structures"), más o menos extensas. Las direcciones estructurales son en efecto muy variadas, dependiendo del acortamiento preferencial inducido por los movimientos oblicuos respecto a la geometría original de los elementos implicados y desarrollados diacrónicamente.

Los límites actuales de la placa del Caribe se desarrollan a lo largo de las fajas marginales deformadas ya descritas. En el caso de los márgenes septentrional y meridional se trata de fallas discretas del tipo transcurrente, sinestral en el primer caso, dextral en el segundo. Como consecuencia de ello, porciones de la corteza caribeña deformada pertenecen hoy a la corteza de las placas adyacentes, y no son más de competencia caribeña s. s. (ej. Cuba, Sistema del Motagua al norte, Cordillera de la Costa al sur, etc.).

En la geometría de los márgenes caribeños deformados s.l., a veces hay zonas de sutura o "terrenos acrecionados", en los cuales están implicadas las unidades tectónicas del tipo ofiolítico de edad Jurásica - Cretácica. La mayoría de tales afloramientos se localizan en Venezuela, Costa Rica, Guatemala y Grandes Antillas. Aunque han sido objeto de numerosos estudios (e.g.: Dengo, 1972), el conocimiento de ellos está lejos de ser exhaustivo, sobretodo en los aspectos de la geometría, del metamorfismo, de la petrología y de la geoquímica.

La indiscutible importancia de comprender el significado de las unidades mencionadas, reside en el hecho de que son los fragmentos deformados más antiguos de la corteza creada en las primeras fases alpinas y de allí conservan la historia geotectónica que da como resultado la configuración actual desde el Mesozoico.

Los modelos geotectónicos relacionados con la placa del Caribe (Anderson \& Schmidt, 1983; Beck, 1986; Dengo, 1985; Morris et al., 1990; Pindell \& Barret, 1990; Ross \& Scotese, 1988; Stephan et al., 1990), están condicionados a las corrientes de pensamiento relacionadas al significado de la corteza caribeña de tipo oceánico:

a. La corteza caribeña actual pertenece, en buena parte, al pacífico, incrustándose progresivamente entre las placas norte y suramericana, "extendiéndose" hacia el este sobre la corteza atlántica. En el curso de su evolución se deforma hasta obducir sobre los márgenes continentales de las Américas.

b. La corteza caribeña actual representa la evolución de áreas marginales "retroarco" con respecto a los dos sistemas principales de subducción, occidental y oriental y ha participado variadamente en la construcción de los márgenes colisionales norte y sur;

c. La corteza caribeña se puede descomponer en dos porciones: una más antigua correlacionable con la terminación occidental de la Tethys Jurásico-Cretácico a través del Proto-Atlántico central y otra, un poco más reciente, que posiblemente constituye el fondo del mar Caribe, cuya pertenencia al Atlántico o al Pacífico es todavía polémica.

Ninguna de las tres interpretaciones puede considerarse única, debido a la ausencia de evidencias analíticas en alguno de los modelos descritos. Probablemente un modelo formulado con base en análisis futuros pudiera ser mucho más articulado y resultaría más complicado, al asumir y descartar analogías y diferencias en el cuadro de la reconstrucción de eventos muchas veces diacrónicos. 


\section{LAS UNIDADES OFIOLITICAS}

Como ya se ha indicado, en los márgenes del Caribe afloran unidades tectónicas de tipo "ofiolítico" y de edad Jurásico-Cretácico, evidenciando la presencia de zonas de "sutura" proto-caribeña en su arquitectura.

Particularmente, los afloramientos más importantes están ubicados en:

a. El margen septentrional (Donnelly et al., 1990; Lewis et al. , 1990 ), del tipo transcurrente sinestral a lo largo de la estructura del Motagua, Polochic y Chamelecon en Guatemala y en las Grandes Antillas. En Guatemala se trata de gruesos cuerpos "abudinados", amigdaloides, que sobrecorren hacia el norte el basamento y la cobertura del bloque Maya y hacia el sur, el basamento del bloque Chortis. En Cuba, se trata de unidades tectónicas sobrecorridas sobre los terrenos de la placa norteamericana que en la Española asumen una doble vergencia. Hay que notar que los elementos proto-caribeños de la isla de Cuba afloran mucho más allá del límite actual de la placa del Caribe. En las islas de Jamaica y Puerto Rico afloran unidades, similares en parte a aquellas de la Española.

b. El margen occidental (Escalante, 1990) del istmo centroamericano, de las penínsulas de Santa Elena, Nicoya y Osa en Costa Rica y de Azuero en Panamá, puede representar, a primera vista, estructuras ligadas a las subduciones activas a lo largo de la Fosa Mesoamericana de la placa de Cocos y en parte de la de Nazca. Sin embargo, y de manera más compleja, pueden asociarse a acortamientos oblicuos a la dirección de la fosa, ligados a las fases tectogenéticas responsables de la combinación de bloques de segundo orden (Chortis, Chorotega ), con anterioridad a la disposición cenozoica.

c. El margen oriental (Maury et al., 1990), de tipo compresivo con subducción activa de la corteza oceánica, atlántica, norte y suramericana bajo el prisma de acreción de Barbados y del arco volcánico de las Antillas Menores, aflora en pequeñas áreas, de las cuales, la más notoria está en la isla Desirade.

d. El margen meridional (Bellizzia \& Dengo, 1990; Case et al., 1990) del tipo transcurrente dextral, cuya ulterior función de empalme entre una porción de la terminación septentrional de los Andes y el arco de las Antillas Menores, es extremamente complejo. La Cordillera de la Costa en Venezuela está constituida, en general, por unidades protocaribeñas, en buena parte obducidas sobre el margen continental de la placa suramericana y que a veces presentan una doble vergencia.

Las unidades ofiolíticas de los márgenes del Caribe están constituidas por rocas intrusivas (del manto y de la corteza), extensamente serpentinizadas y por secuencias efusivas (basaltos almohadillados y masivos), algunas veces con extensa cobertura sedimentaria (jaspes, radiolaritas y secuencias pre-flysch). Se encuentran alóctonas con corrimientos basales más o menos evidentes y subdivisibles en unidades de orden inferior a lo largo de contactos, a menudo poco claros; a veces se encuentran en cuerpos abudinados en el interior de complejos de tipo "melange".

En los lugares de mayor deformación, cuando se presenta un contraste de competencia entre los litotipos, en aquellos más dúctiles se evidencian por lo menos dos fases penetrativas: en la mayoría de los casos se trata de pliegues isoclinales $\mathrm{F} 1$ con foliaciones de plano axial S1, replegadas en pliegues más amplios F2 con clivaje de crenulación S2 y con orientaciones variables.

Las ofiolitas caribeñas se encuentran a menudo metamorfizadas; las facies varían de la prehnita-pumpellita a facies de mayor grado con glaucofano y lawsonita, llegando hasta los esquistos verdes y anfibolita. En los litotipos más significativos no está todavía clara la relación entre la deformación y el metamorfismo, aunque existen algunas evidencias de que este último ocurrió en las mismas condiciones dinámicas en que se produjo la deformación. La deformación y el metamorfismo son mecanismos ligados a la formación de complejos de subducción, ya sea por "underplating", por acreción o por obducciones sucesivas.

\section{GUATEMALA}

En Guatemala está en estudio la "zona de sutura del Motagua" (Finch \& Dengo, 1990), donde las unidades ofiolíticas afloran a lo largo de las fallas transformadas de Polochic y Motagua (Fig. 2). 


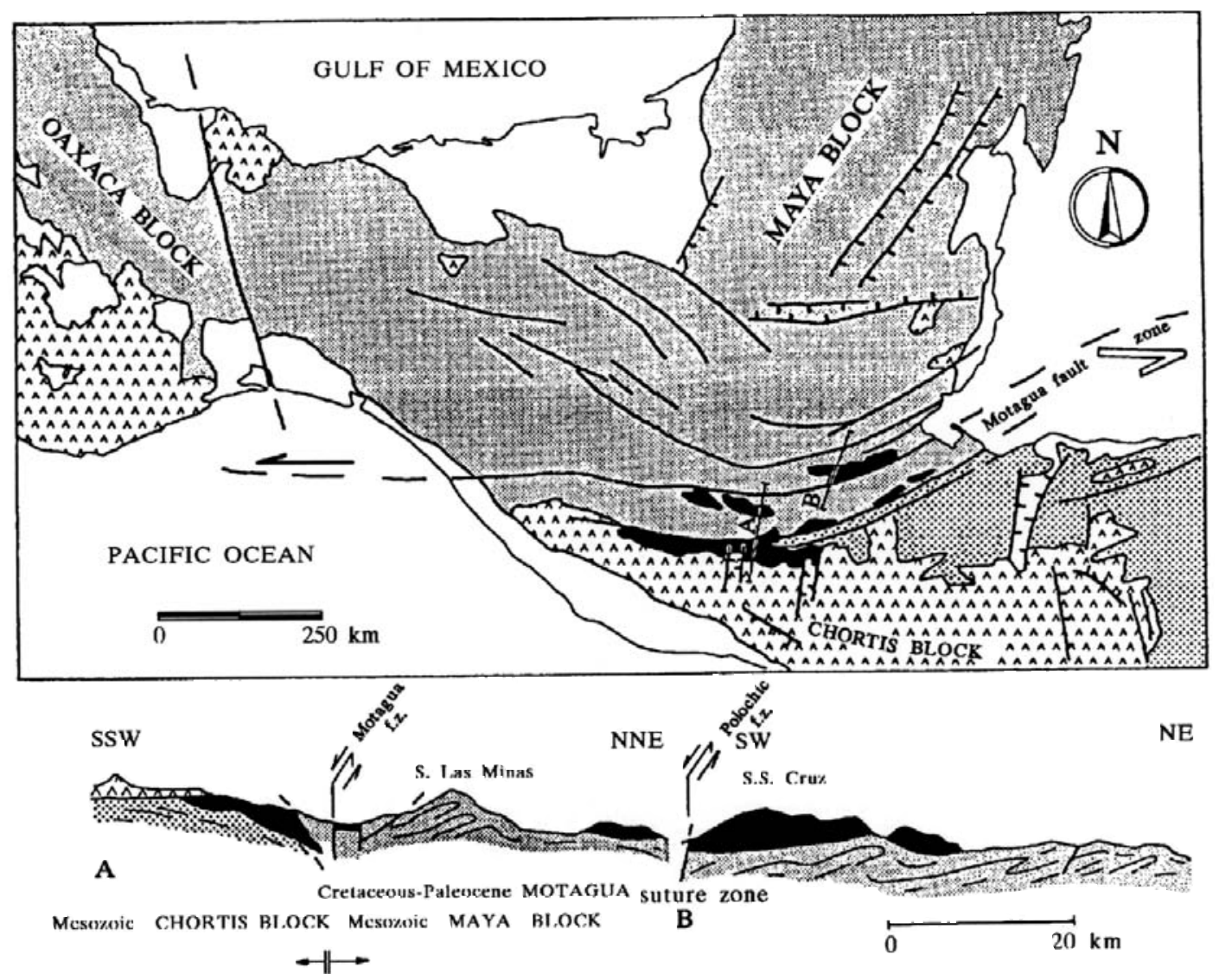

\section{|LEGEND}

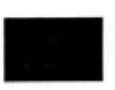

Ultrabasic rocks, basalts and radiolarites of the Motagua suture zone (Jurassic-Cretaceous)

$\square$ Recent sedimentary rocks

Tertiary-Quaternary volcanic arc: intrusive A
Paleozoic-Mesozoic and Tertiary sequences of the continental Maya Block (including Peten folded belt and Yucatan platform)

Paleozoic-Mesozoic sequences of the continental Chortis Block

Fig. 2. Esquema tectónico de la zona de sutura de Motagua, Guatemala (modificado de Dengo, 1986 y del mapa geológico de la República de Guatemala).

Estas últimas fallas representan secciones discretas del Terciario Tardío que están sobreimpuestas a una zona de sutura del Mesozoico-Terciario originada por la colisión transpresiva de los bloques continentales Maya (México meridional, Guatemala septentrional y Belice) y Chortis (Guatemala, Honduras, El Salvador y Nicaragua), con la consiguiente destrucción de una área oceánica interpuesta entre ellos. Los residuos deformados de esta área afloran en una ancha zona de cizalla, asociada a cuerpos abudinados, ubicados a lo largo de las fallas, o como unidades tectónicas obducidas sobre el bloque Maya, con vergencia generalmente septentrional (Verapaz, Sierra de Santa Cruz, Valle del Motagua, Juan de Paz) y sobre el bloque Chortis con 
vergencia meridional (El Tambor). Las unidades ofiolíticas se presentan en una serie de escamas tectónicas asociadas a un sobrecorrimiento. La reconstrucción de los márgenes continentales mesozoicos Maya y Chortis resulta complicada por el hecho de que la deformación ha llegado mucho más allá de los mismos márgenes, a menudo borrando la continuidad física original entre ellos y la zona de laceración oceánica.

En general se trata de peridotitas serpentinizadas y serpentinitas, que pasan a gabros y a doleritas, a los cuales siguen en contacto casi siempre mecánico, basaltos y lavas almohadilladas. La cobertura sedimentaria, mayormente representada en las Unidades del Bloque Chortis (Formación El Tambor y similares), está constituida por jaspes y radiolaritas, intercalados con basaltos almohadillados y con una secuencia volcánico-sedimentaria que pasa a otra detrítica hasta detrítico-carbonática.

La edad de esta serie ofiolítica debe estar comprendida entre el Jurásico Tardío y el Cretácico. La deformación está representada por la presencia de por lo menos dos fases dúctiles penetrativas seguidas de una densa red de pares conjugados. Los litotipos están generalmente metamorfizados a la facies de esquistos verdes y anfibolita. La edad de la primera deformación es referible al Cretácico, mientras que la obducción de los fragmentos ofiolíticos deben haberse iniciado en la orogénesis Laramidiana.

\section{COSTA RICA}

En Costa Rica (Fig. 3) se realizó una campaña regional sobre la Unidad de Santa Elena y el Complejo de Nicoya (Azema et al., 1984; Gursky, 1988; Kujpers, 1980; Meschede et al., 1988).

Los terrenos de Santa Elena y Nicoya afloran en escamas tectónicas sobrepuestas según la geometría de una zona de arco externo en el margen interno de la Fosa Mesoamericana. Los estudios de carácter estructural realizados por algunos de los autores citados hacen suponer que antes de la geometría actual, las unidades se estructuraron en un campo de esfuerzos de diferente orientación a aquel inducido actualmente en la fosa y la convergencia probablemente fue hacia los cuadrantes meridionales.

La unidad de Santa Elena esta sobrepuesta tectónicamente al Complejo de Nicoya que a su vez se subdivide en dos unidades principales, una más antigua (Matapalo) y una más reciente (Esperanza), sobrepuestas en orden inverso o normal conforme a las interpretaciones de diferentes autores. Una de las interpretaciones mencionadas, es aquella que prevé no una sobreposición tectónica sino una secuencia normal de un complejo inferior (equivalente a Matapalo, p.p.) a un complejo superior (equivalente a Esperanza, p. p.), separados por una serie sedimentaria constituida por jaspes.

Disponiendo los diversos afloramientos en una única secuencia litoestratigráfica compuesta, se identifican (desde la parte inferior): peridotitas serpentinizadas y serpentinitas, gabros (Santa Elena), seguidos de basaltos masivos y almohadillados, con interacalaciones de plagiogranitos, gabros y doleritas, que pasan a jaspes y radiolaritas (Matapalo), a los cuales siguen basaltos y niveles volcano-sedimentarios alternados con jaspes y radiolaritas (Esperanza).

Todos los litotipos de las unidades mencionadas están afectados por una intensa deformación dúctil penetrativa, que varía en función del grado de competencia de los materiales. Las fases deformadas son por lo menos dos, y para algunos autores pudiesen llegar a cuatro. El metamorfismo regional, donde este existe, es bajo, haciendo suponer que tales cuerpos rocosos no alcanzaron una gran profundidad en la zona de subducción.

Las unidades ofiolíticas de Costa Rica están probablemente relacionadas con la deformación tardío mesozoica y terciaria de amplias porciones de zonas oceánicas ubicadas en el paso entre el Pacífico y la compleja zona protocaribeña.

\section{LA ESPAÑOLA}

En la República Dominicana (Fig. 4), se realizó un recorrido de una transversal en la Cordillera Central, que junto con los datos de la bibliografía (Lewis et al., 1983, 1990), ha servido para formarse una idea regional de la problemática relacionada con el alineamiento ofiolítico de las Grandes Antillas.

Las unidades ofiolíticas de La Española, incluidas aquellas de dudosa ubicación en la Cordillera Meridional de Haití, afloran a lo largo de una zona de fuerte cizalla con orientación Oeste-Este, inducida por una cizalla transpresional sinestral. 

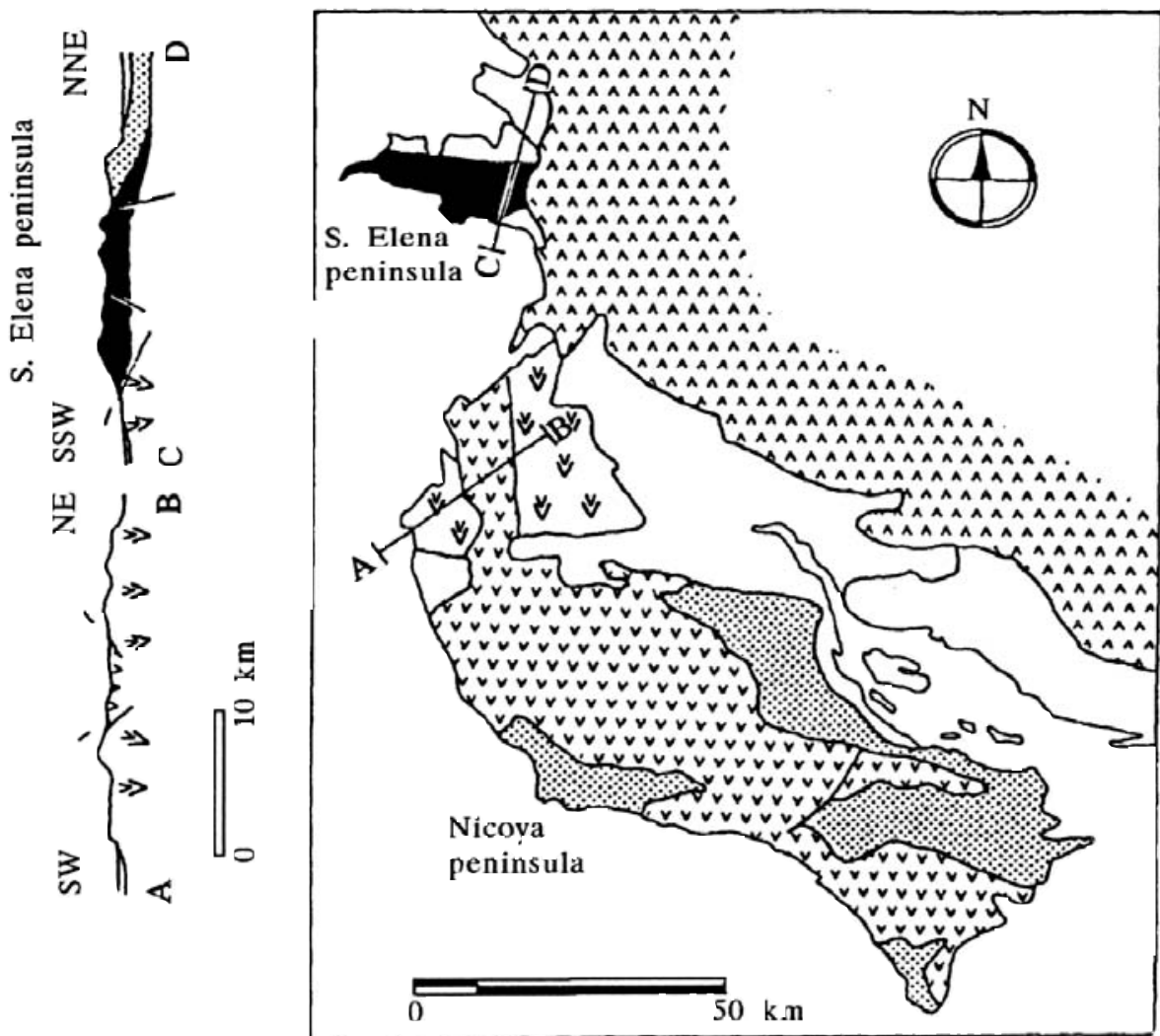

I.F.GFNI

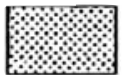

Terrigenous and/or carbonatic

sequences (Cretaceous-Tertiary)
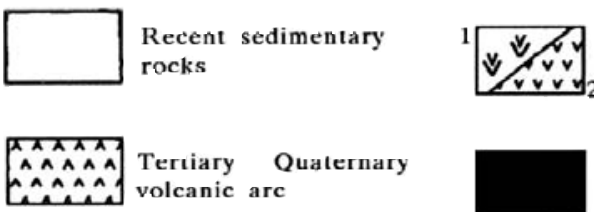

Pillow and massive basalts, with radiolarites: 1) Upper Jurassic-Lower Cretaceous (Matapalo U.); 2) Middle-Upper Cretaceous (Espcranza U.)

AnA. volcanic arc

Ultrabasic complex: harzburgites, peridotites and gabros, serpentinites: Jurassic (S.Elena U.)

Fig. 3. Esquema tectónico de las penínsulas de S. Elena y Nicoya, Costa Rica (de Kuijpers, 1980; Azema et al, 1984; Gursky, 1988; Meschede et al., 1988).

Las unidades tectónicas están sobrepuestas recíprocamente a lo largo de superficies que a menudo son próximas a la vertical, configurando una doble vergencia en sentido meridional. Las vertientes meridionales del sistema deformado presentan características de un antiguo prisma de acreción, en el cual las unidades de corteza "oceánica" están sobrepuestas a los potentes depósitos terrígenos de una cuenca de arco frontal Mesozoico-Terciario.

Afloran peridotitas más o menos serpentinizadas, serpentinitas y gabros, a las cuales siguen potentes series de lavas basálticas y rocas volcano-sedimentarias con pocas intercalaciones de jaspes y radiolaritas (Complejo Duarte), continuando con sedimentos volcánicos y lavas con 


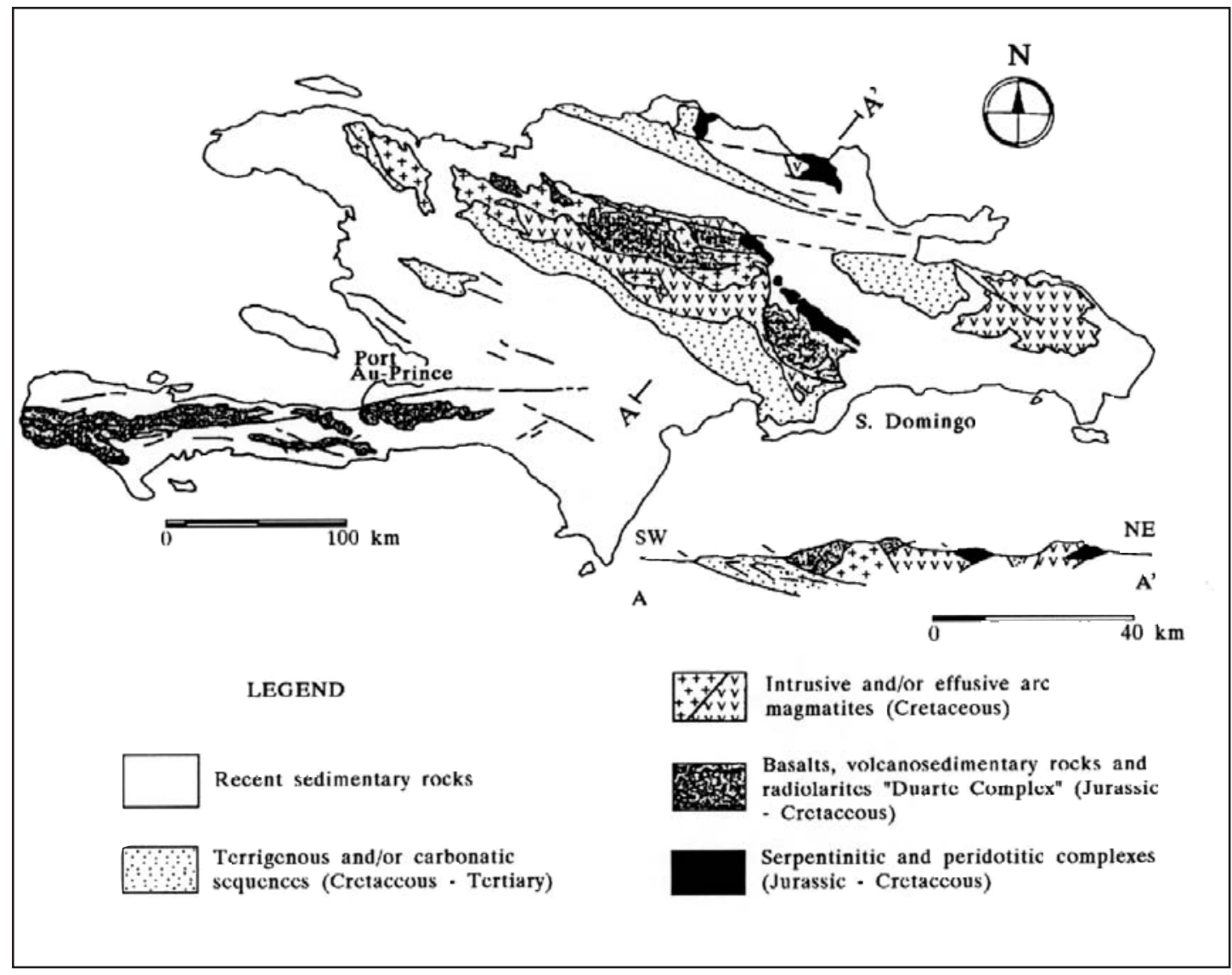

Fig. 4. Esquema tectónico generalizado de La Española (modificado de Lewis \& Draper, 1983).

características de arco insular. El conjunto está intruido por magmas ácidos que afloran en voluminosos cuerpos de tonalitas.

Las edades deben referirse al Jurásico-Cretácico para la porción oceánica más evidente y al Cretácico-Terciario Temprano para aquella de los arcos.

Especialmente, los litotipos “oceánicos” se presentan muy deformados dúctilmente y a veces metamorfizados. Los otros terrenos manifiestan deformación intensa de cizalla. La estructuración de las unidades señala una deformación temporal casi continua del Laramido al Terciario.

El referir el origen de las unidades ofiolíticas de La Española y las de las Grandes Antillas a una u otra zona de corteza oceánica Mesozoica, representa uno de los grandes problemas de la geología de los márgenes caribeños. La tentativa de aportar soluciones a tales problemas ha conducido a la formulación de diversos modelos.

\section{VENEZUELA}

En Venezuela se ha levantado una transversal en la Cordillera de la Costa, con tal nombre se comprende el orógeno que une en dirección Este-Oeste el segmento nororiental de los Andes (Andes de Mérida) con el arco volcánico de las Antillas Menores (Bellizzia, 1986; Bellizzia \& Dengo, 1990).

Se considera que esta cordillera se extiende desde la llamada depresión de Barquisimeto, al oeste, hasta poco más al este de las islas de Trinidad y Tobago. Hacia el sur está limitada por el cratón de Guayana, área estable de la placa 
suramericana, sobre la cual se sobreponen las unidades frontales externas de la banda móvil de dicho sistema. El límite septentrional no es fácilmente definible por la presencia del mar del Caribe y del prisma de acreción de Colombia y Venezuela: se supone que dicho límite se halla al norte del alineamiento de la península de la Guajira - Antillas Holandesas - islas venezolanas.

La Cordillera de la Costa se extiende longitudinalmente por cerca de $1.000 \mathrm{~km}$ y por 100 $\mathrm{km}$ transversalmente y está constituido por una serie de unidades apiladas con vergencias generalmente meridionales. Resulta difícil reconocer ondulaciones axiales notables en la banda deformada por la presencia de una densa red de deformaciones frágiles del tipo transcurrente dextral, con sistemas sintéticos conjugados y secundariamente antitéticos. El estilo tectónico resultante es con altos y bajos estructurales, de los cuales estos últimos son propios y verdaderos sinclinales.

El espesor de la corteza, según los datos geofísicos (Case \& Holcombe, 1980; Graterol \& Fonseca, 1978), debe girar en torno a los 25-35 km.

Un perfil representativo de la Cordillera de la Costa, se sitúa aproximadamente en dirección norte-sur un poco al oeste del meridiano de Caracas. A lo largo de este perfil, se reconocen las siguientes unidades (Navarro, 1983; Beck, 1985, 1986; Bellizzia, 1986; Navarro, 1989; Navarro et al., 1988; Carnemolla et al., 1990 y Ostos, 1991) que son de norte a sur (Fig. 5):

Unidad Franja Costera: Yace en sobrecorrimiento a lo largo de un contacto con buzamiento norte, a veces de alto ángulo, sobre la Unidad de la Cordillera de la Costa. Se trata de una secuencia mesozoica de terrenos terrígeno-carbonáticos y volcano-sedimentarios, con intercalaciones de niveles de lavas básicas, que contiene "boudines" de dimensiones variables de rocas máficas y ultramáficas (fases Tacagua y Nirgua; Navarro et al., 1988). La secuencia es metamórfizada (facies de esquistos verdes) y deformada dúctilmente en dos fases. Algunas características generales de campo son muy similares a algunas secuencias franciscanas del norte de California.

Unidad de la Cordillera de la Costa: Aflora en una dorsal alta y paralela a la costa, constituyendo un levantamiento que separa la unidad costera de las meridionales. Está limitada al sur por la estructura transcurrente subvertical de la falla de La Victoria. Está constituida por un basamento Paleozoico - Precámbrico (Complejo de Sebastopol, Complejo El Avila, Augengneis de Peña de Mora, Esquisto de San Julián), y de una cobertura discordante de tipo carbonático o terrígena con intercalaciones volcánicas, de edad mesozoica (formaciones Las Brisas, Antímano, Las Mercedes, Chuspita) (Urbani y Ostos; 1989). Dichos terrenos están metamorfizados en la facies de los esquistos verdes primordialmente y deformados, con foliaciones S1 de plano axial (ejes orientados de SSE a ESE) y un clivaje de crenulación S2 (ejes orientados OSO a SSO).

Unidad de Paracotos: Aflora en la Serranía del Interior en contacto tectónico con la unidad de la Cordillera de la Costa, a lo largo de la falla La Victoria. A veces está sobrecorrida sobre la última, con sobrecorrimientos cortados por la falla. Hacia el sur se emplaza sobre unidades piemontinas.

Esta unidad se ubica en un sinforme estrecho y asimétrico con el lado septentrional más desarrollado, de modo que las superficies de sobreposición resultan rotadas hacia el sur, con el resultado de que a lo largo del frente meridional las unidades más altas del complejo se sobreponen directamente a aquellas más externas. La disposición "en echelon" de cada unidad, desde el oeste hacia el este, esta ligada a los desplazamientos transcurrentes que abarcan toda la cordillera. Esta tectónica hace que los contactos de sobrecorrimiento entre las diversas unidades hayan sido reutilizados y en parte borrados por estructuras subverticales (Fallas de Santa Rosa, de Agua Fría, etc.).

Unidad Caucagua-El Tinaco: Siguiendo la literatura, se incluyen en esta unidad terrenos y formaciones identificadas en buena parte de la Cordillera de la Costa, cuyas correlaciones, a menudo, no son del todo claras. Está constituida por un basamento premesozoico (Complejo de El Tinaco), que incluye meta-sedimentos con raras meta-volcánicas en la facies anfibolita (Gneis de Aguadita), y esquistos, metaconglomerados y meta-arcosas en la facies de los esquistos verdes (Esquistos de Tinapú). Hacia el oeste dicho basamento está a veces atravesado por filones de rocas máficas, que pueden aflorar por encima del mismo (discordancia o contacto mecánico), constituidas por dunitas y gabros serpentinizados 

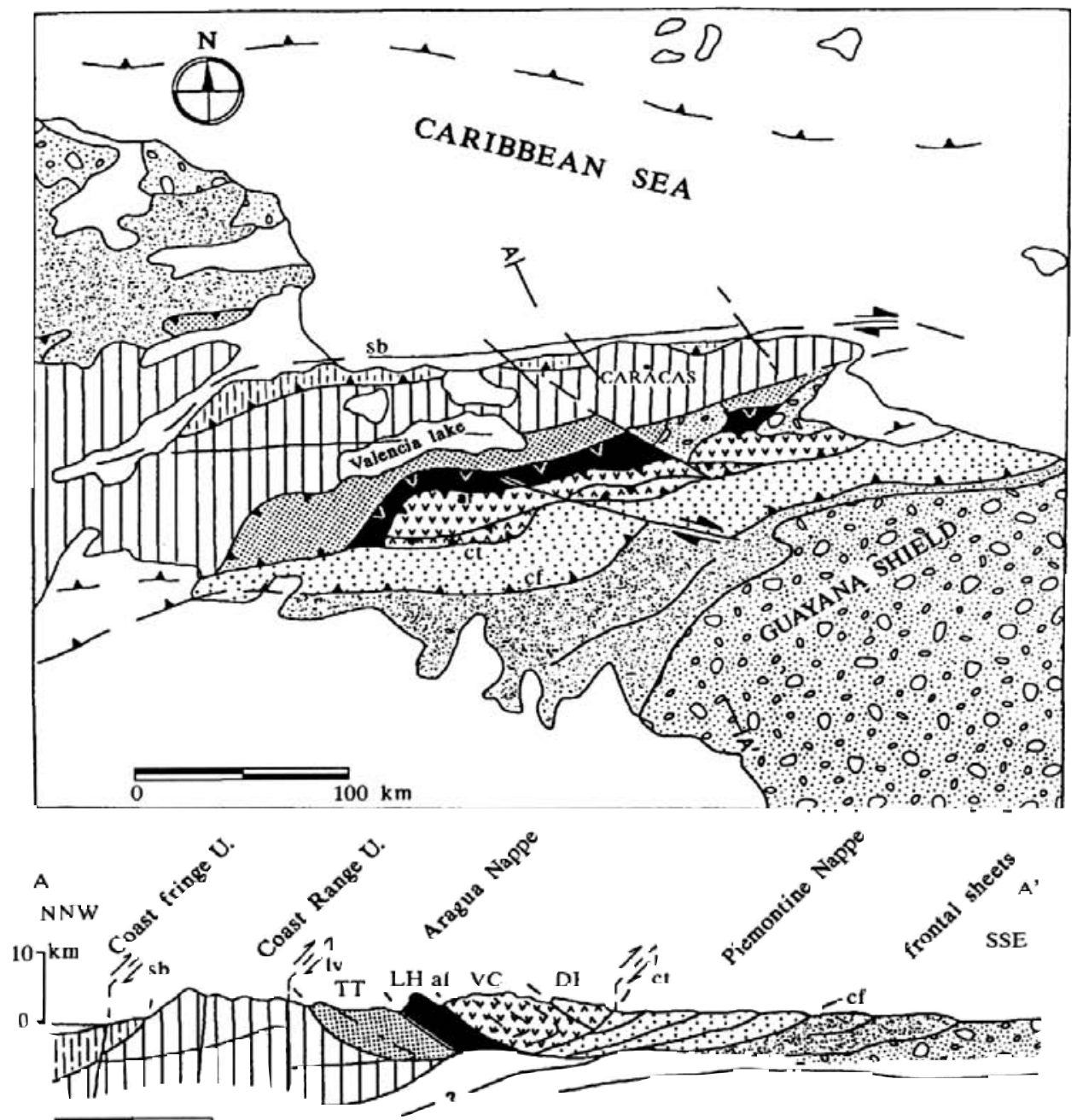

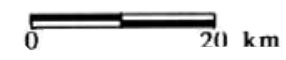

LEGEND

Dos Hermanas Unit (DH) andcestic
sequences (Cretaceous)

Fovvy Villa de Cura Units (VC): basalts and

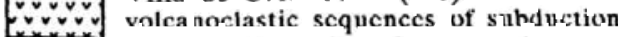
complex (Jurassic Cretactous)

Loma de Hierro Unil ( $\mathrm{H}$ ): ultrabasic rucks, hasalts and siliceous carbonatic sequences (Jurassic Cretaccous) Caucagua El Tinaco Únil (TT): contincntal basement. basalts and carbonatic sequences (Palcozoic Cretaceous)
Costal Frınge Uni: (FC): terrigenous
and carbonatic sequences, basalts and voleanoclastics (Iurassic Cretaccous Coasta Range Unit: continental ПП basement, carbonatic and siltitic hasement, carbo natic and siltitic
sequences, intrusives (Paleozoic Cretaceous) Piemontine flysch thrust sheets
(Crctaccous Paleogene)

ta. Folded terrigenous sequences (1) lizo Miscene)

0.0 Tcrrigenous sequences ( $\mathrm{M}$ io

$\therefore$ O. Pleistocene) of the stable Guayana shicld

Fig. 5. Esquema tectónico del sector central de la Cordillera de la Costa, Venezuela (modificado de Beck, 1986). (sb) falla de San Sebastián; (lv) falla de La Victoria; (af) falla de Agua Fría; (ct) corrimiento Cantagallo; (cf) corrimiento frontal. 
(Peridotita de Tinaquillo), de edad Jurásica a pre-Albiense. Encima, en discordancia y directamente sobre el basamento, yace una secuencia volcano-sedimentaria de edad probablemente Cretácica temprana, que varía de lugar a lugar a lo largo del eje del orógeno, de forma tal que hace dudar sobre su continuidad física original. En general, se trata de secuencias terrígenas más o menos proximales (areniscas arcósicas y conglomerados), que pasan a calizas y calcarenitas. Además, en la secuencia se intercalan brechas y basaltos almohadillados con espesores variables. $\mathrm{La}$ edad debería corresponder al Cretácico Tardío.

Del oeste hacia el este existen diferencias pronunciadas en las secuencias y, especialmente, en el metamorfismo. Al oeste, las formaciones Pilancones, Querecual, La Luna y las brechas de Sabana Larga no presentan metamorfismo; hacia el oriente, las formaciones Las Placitas y Aragita tienen metamorfismo de bajo grado. Más hacia el este, a la altura del perfil, afloran meta-areniscas, meta-conglomerados y mármoles de la Formación Tucutunemo con intercalaciones de metabasaltos (Miembro Los Naranjos) que presentan metamorfismo en la facies de esquistos verdes y las dos fases de deformación dúctil penetrativa reconocidas en las otras unidades internas del orógeno.

Unidad Loma de Hierro: Esta constituida por una secuencia de peridotitas serpentinizadas y gabros cumulíticos, cuya edad no debe ser más antigua que Jurásico Tardío, seguidas en algunas localidades de metabasaltos, con intercalaciones de mármoles silicificados ("Capas del Río Guare"), de edad Jurásico Tardío Cretácico Temprano. En contacto prevalentemente mecánico siguen lavas masivas (Formación Tiara), principalmente metabasaltos y metadoleritas, a veces atravesados por filones de microgabros, probablemente de edad Cretácico Temprano. Siguen en contacto poco claro, meta-pelitas filíticas y meta-areniscas con intercalaciones de calizas gris clara y conglomerados y limolitas volcanoclásticas (Formación Paracotos) de edad Cretácica. La recristalización metamórfica varia de nivel a nivel, en general se trata de esquistos verdes, en los litotipos menos competentes con presencia de las dos fases deformativas ya descritas para las otras unidades, con foliación de plano axial S1 y clivaje de crenulación S2 superimpuesto.
Unidad de Villa de Cura: Esta unidad ha sido subdividida en tres subunidades (Navarro, 1983; Ostos \& Navarro, 1986), entre las cuales las relaciones no están muy bien definidas, al punto que no hay información sobre la geometría de las escamas, probablemente a causa del intenso plegamiento que ha abarcado todo el complejo.

Está constituida por meta-lavas masivas a foliadas, con un metamorfismo de alta p/T, del tipo esquistos azules con glaucofana y clinozoisita (Subunidad de meta-lavas); meta-piroclástitas y meta-lavas subordinadas, foliadas, en facies metamórficas de los esquistos azules con glaucofana y lawsonita (Subunidad de meta-tobas); metavolcánitas y secuencias meta-volcano-sedimentarias hasta meta-limolitas y jaspes foliados, con metamorfismo de esquistos azules con glaucofana y barroisita (Subunidad de Granofels). La edad del complejo es probablemente Jurásico Tardío - Cretácico Temprano, pero faltan referencias precisas de la estratigrafía.

Las características de la deformación son compatibles con aquellas de las otras unidades descritas, con foliación de plano axial S1 afectada por clivaje de crenulación S2.

Unidad Dos Hermanas: Parece ser la unidad más joven del conjunto y yace sobre la Unidad de Villa de Cura (Subunidad de Granofels) con contacto poco claro, mecánico o no, y en contacto de sobrecorrimiento variadamente inclinado hacia el norte sobre las unidades piemontinas mas externas, aunque se puede inferir una continuación originaria lateral con algunas secuencias de estas últimas (Formación Garrapata).

Está compuesta por brechas de flujo y rocas volcanoclásticas basáltico-andesíticas con metamorfismo en las facies prehnita-pumpellita. Algunos datos geocronológicos (Navarro, 1983; Ostos \& Navarro, 1986 y Urbani et al., 1991) hacen remontar los litotipos descritos al Cretácico Tardío. No se han identificado estructuras significativas de deformación dúctil.

Unidades Piemontinas: Afloran al sur debajo del complejo antes descrito y se sobreponen al cratón de Guayana a través de una serie de escamas frontales que constituyen el límite meridional de la Cordillera de la Costa. Se trata de un complejo de unidades alóctonas no metamorfizadas imbricadas con vergencia meridional; las deformaciones dúctiles a escala macroscópica están 
representadas por pliegues angostos hasta "chevron", a menudo volcados.

\section{ASPECTOS PETROGRAFICOS DE LOS LITOTIPOS OFIOLITICOS}

Las investigaciones efectuadas en Guatemala, Costa Rica y La Española, han permitido una primera caracterización petrográfica de los litotipos ofiolíticos. Particularmente de Guatemala se han analizado lavas almohadilladas (GUA 18A) y niveles de anfibolita (GUA4, GUA8); de Costa Rica algunos basaltos (SJOl, $22,32,35$ ), a los cuales se han adjuntado, para la comparación, los datos analíticos de la literatura sobre basaltos provenientes de la península de Nicoya; en La Española secuencias caracterizadas por alternancia de lavas (SDQ 1,2,3) y piroclastos (SDQ 4,5) de composición basáltica, a las que se han adjuntado, para la comparación, análisis químicos de basaltos pertenecientes al Complejo Duarte.

Del estudio un poco más detallado de una sección de la Cordillera de la Costa en Venezuela, resultó que algunas unidades presentan secuencias mesozoicas máficas y ultramáficas del manto y de la corteza que a veces atraviesan el basamento continental antiguo. Casi todas las unidades reconocidas poseen más o menos extensas coberturas volcánicas, generalmente básicas, intercaladas y/o recubiertas por rocas sedimentarias y volcano-sedimentarias. La edad, a confirmar con dataciones radiométricas, actualmente en curso, debería corresponder al Cretácico Temprano.

El estudio petrográfico se realizó sobre secciones delgadas de muestras representativas de las litologías magmáticas de edad JurásicaCretácica, principalmente las unidades descritas a lo largo del perfil. Se determinaron las paragénesis principales, útiles para la definición del carácter magmático y del metamorfismo.

Los litotipos reconocidos pertenecen a las unidades ya descritas:

Unidad Franja Costera: Esquistos albítico-actinolítico-epidótico-cloríticos de la Fase Tacagua (VNZ 75-82). Las características mineralógicas y texturales sugieren que estas rocas provienen originalmente de series volcanoclásticas básicas. Son evidentes fenómenos de saussuritización de la plagioclasa con neoformación de plagioclasa rica en albita, calcita y epidoto-clinozoisita; la asociación actinolita-clorita caracteriza un metamorfismo en la facies de los esquistos verdes.

Unidad Caucagua-El Tinaco: Meta-lavas con textura más o menos porfírica con plagioclasa, actinolita, clorita, calcita y esquistos anfibólicos con actinolita, clinozoisita, clorita y plagioclasa (VNZ 13, 35, 67, 94, 97 y 101), pertenecientes al Miembro Los Naranjos de la Formación Tucutunemo. Meta-lavas (con estructuras almohadilladas) y meta-doleritas con clinopiroxeno, plagioclasa y actinolita de la Formación Pilancones (VNZ 86-88). Todas las litologías magmáticas referidas a esta unidad se encuentran en la facies de los esquistos verdes.

Unidad Loma de Hierro: Rocas ultramáficas constituidas por peridotitas más o menos serpentinizadas, gabros con clinopiroxeno, plagioclasa alterada y pumpellita (VNZ 64-66); basaltos toleíticos con textura porfídica, extensamente espilitizados y con la matriz cloritizada (Formación Tiara). Estas litologías presentan metamorfismo en la facies de los esquistos verdes (VNZ 17).

Unidad Villa de Cura: Meta-volcanitas intermedias a félsicas, caracterizadas por una paragénesis de alta presión (Subunidad de Granofels; VCg). Los litotipos (VNZ 104 -108) presentan textura esquistosa. Las asociaciones mineralógicas están constituidas por plagioclasa, epidoto, clorita, actinolita, glaucofana, barroisita y estilpnomelana. La presencia de barroisita formada a expensas de la actinolita, coexistente con glaucofana y con epidoto sugiere condiciones de presión similares a aquellas indicadas por la presencia de glaucofana, pero temperatura más elevada (ERNST, 1979). Meta-lavas masivas (VNZ $111,112,114)$ en las cuales se evidencia una textura porfídica con fenocristales de clinopiroxeno zonado (Subunidad de Metalavas; VCm). El grado metamórfico se vuelca hacia la facies de los esquistos azules y está caracterizado por la presencia de glaucofana-crossita que crece sobre los bordes del piroxeno. En la misma subunidad han sido encontrados esquistos con lawsonita - epidoto - clorita (VNZ 109,110,113) que sugieren la presencia de una alternancia originaria de lavas y productos piroclásticos. Esquistos (VNZ 115) 
con una paragénesis de alta $\mathrm{p} / \mathrm{T}$ con plagioclasa, epidoto, actinolita, clorita, glaucofana-crossita (Subunidad de Meta-tobas; VCmt) son derivados de secuencias piroclásticas.

Unidad Dos Hermanas: Lavas, brechas y piroclastitas con composición andesítica y asociaciones metamórficas de bajo grado con prehnita-pumpellita-clorita.

\section{ASPECTOS GEOQUIMICOS}

Los análisis petrográficos han permitido la identificación de las características principales de los litotipos observados en el perfil a través de la Cordillera de la Costa, tanto desde el punto de vista de la afinidad magmática como del grado metamórfico. Las rocas analizadas son predominante de composición basalto-gabro, que sufrieron un metamorfismo en condiciones variables, desde la facies de los esquistos verdes hasta la de los esquistos azules, pumpellita-actinolita y prehnita-pumpellita.

Los análisis químicos por FRX de los elementos mayoritarios y traza, se han llevados a cabo sobre muestras representativas de las diferentes litologías pertenecientes a las unidades magmáticas que afloran en Guatemala, Costa Rica, la Española (Tabla 1) y a lo largo de la transversal de la Cordillera de la Costa de Venezuela (Tabla 2). Los valores de $\mathrm{Mg}$ (relación $\mathrm{Mg} / \mathrm{Mg}$ $+\mathrm{Fe}^{2}+$ asumiendo $\left.\mathrm{Fe}_{2} \mathrm{O}_{3} / \mathrm{FeO}=0,15\right)$ son altos y se ubican entre 0,52 y 0,76 (excluyendo las rocas de tipo cumulítico del complejo peridotítico-gabroide de la Unidad Loma de Hierro que presentan un $\mathrm{Mg}$ variable entre el rango 0,83-0,86). Algunas de las rocas meta-volcánicas parecen representar magmas primarios de tipo basáltico.

Los diagramas de variación, asumiendo $\mathrm{MgO}$ como índice de diferenciación $\left(\mathrm{MgO}-\mathrm{P}_{2} \mathrm{O}_{5}\right.$, $\mathrm{MgO}-\mathrm{Na}_{2} \mathrm{O}, \mathrm{MgO}-\mathrm{CaO}, \mathrm{MgO}-\mathrm{FeO}, \mathrm{MgO}-\mathrm{Al}_{2} \mathrm{O}_{3}$, $\mathrm{MgO}_{-} \mathrm{TiO}_{2}, \quad \mathrm{MgO}-\mathrm{SiO}_{2}, \mathrm{MgO}-(\mathrm{La}+\mathrm{Ce}+\mathrm{Nd})$, $\mathrm{MgO}-\mathrm{Sr}$, MgO-Ba, MgO-Rb, $\mathrm{MgO}-(\mathrm{Cr}+\mathrm{Ni})$ ), muestran distribuciones dispersas y sobrepuestas, aunque algunas leves distinciones pueden existir dentro de cada unidad y tipo litológico. Así, las unidades de Villa de Cura y Dos Hermanas se caracterizan por su bajo contenido en REE, $\mathrm{Nb}$ y $\mathrm{Zr}$, las Subunidades de Granofels (VCg) y de Metalavas (VCcn) por un alto contenido de $\mathrm{Ba}$, superior al de la Subunidad de Meta-tobas (VCch) de la Unidad de Villa de Cura y de la Unidad Dos Hermanas. La Formación Pilancones de la Unidad Caucagua-El Tinaco (TTpil) muestra contenidos de Ba y Sr muchos más altos. Las rocas de tipo cumulítico de la Unidad de Loma de Hierro (LH) muestran bajos contenidos en $\mathrm{TiO}_{2}, \mathrm{FeO}$, $\mathrm{P}_{2} \mathrm{O}_{5}, \mathrm{Zr}$, Y, y altos contenidos en $\mathrm{Al}_{2} \mathrm{O}_{3}, \mathrm{CaO}$, $\mathrm{Cr}$, Ni y Sr. En tales rocas la composición química puede haberse modificado por los eventos sucesivos, tales como la movilización selectiva de los elementos durante el metamorfismo.

Algunas informaciones de base se pueden obtener del diagrama Ni contra Ti/Cr (Beccaluva et al., 1979). En las figuras 6 y 7 la totalidad de las muestras de Costa Rica, Guatemala y La Española y la mayor parte de las muestras de las Unidades de la Franja Costera, Caucagua-El Tinaco y Loma de Hierro se ubican en el campo de los productos con altos contenidos de $\mathrm{TiO}_{2}$, a excepción de algunas muestras de la Unidad Villa de Cura y Dos Hermanas que lo hacen en el campo de los basaltos con valores bajos en $\mathrm{TiO}_{2}$.

Antes de valorar el significado geoquímico de los otros elementos traza en las interpretaciones de los procesos ígneos originales, es necesario considerar la influencia del metamorfismo y de la alteración sobre la movilización de los elementos. Elementos de gran radio iónico (LIRE, $\mathrm{K}, \mathrm{Rb}, \mathrm{Ba}, \mathrm{Sr}$ ) se mueven con facilidad en las rocas metamórficas. Al contrario, los elementos de alta fuerza de campo (HFSE, como $\mathrm{Zr}, \mathrm{Nb}$, Ti, $\mathrm{Y}$ ), y las tierras raras (REE) se consideran casi inmóviles en los procesos metamórficos. En el diagrama Ti/10 3 contra Zr (Pearce, 1982) (Fig. 8) se observa una correlación lineal entre los dos elementos y se nota como la mayor parte de las muestras pertenecientes a las Unidad de la Franja Costera, Caucagua -El Tinaco y Loma de Hiero se ubican en el campo MORB; algunas muestras de la Unidad Villa de Cura muestran una dispersión significativa en el campo IAT.

En conclusión, las distribuciones de los HFSE en los diagramas indican una afinidad toleítica de tipo MORB.

Estudiando los valores medios obtenidos en las diferentes unidades se puede intentar algunos suposiciones sobre las posibles contribuciones magmáticas:

1) Los elementos hidromagmatófilos presentes en las rocas de la Unidad Franja Costera y de las formaciones Tucutunemo y Pilancones de 


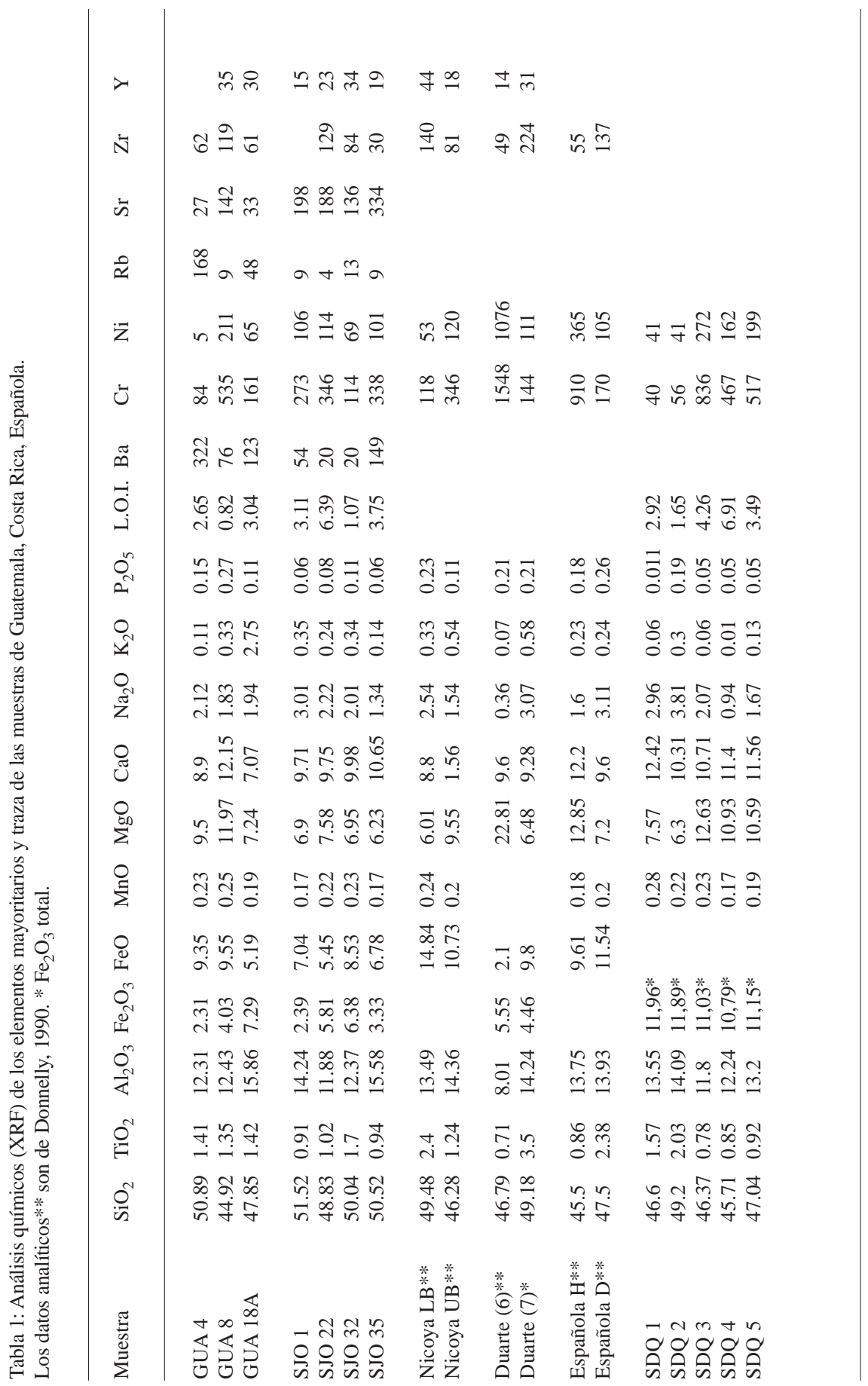




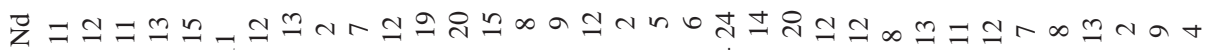
U

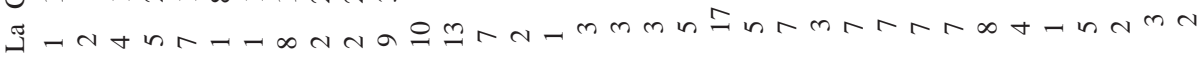

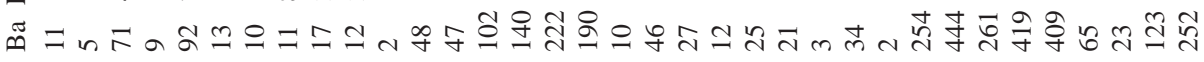

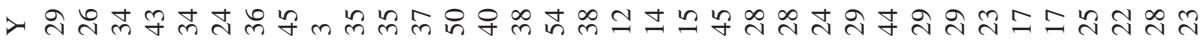

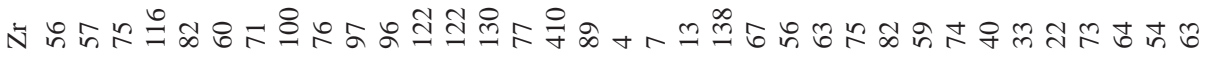

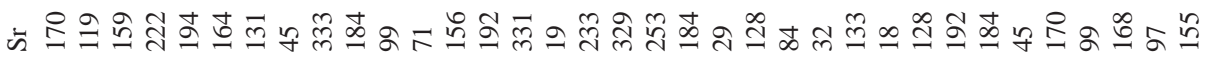
๙ै

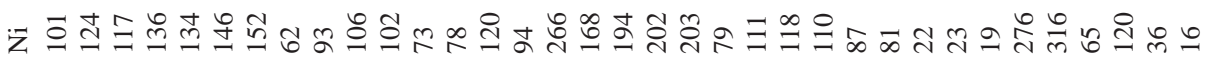

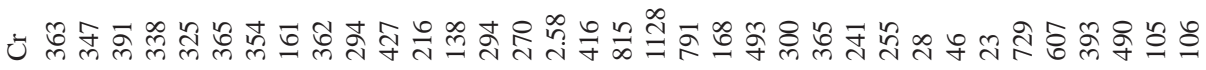

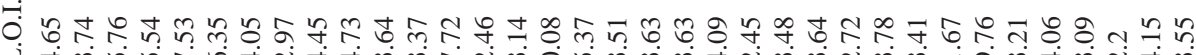
$0^{n}-\infty$

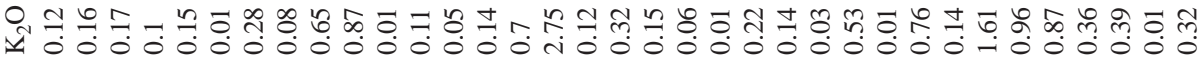
そึ

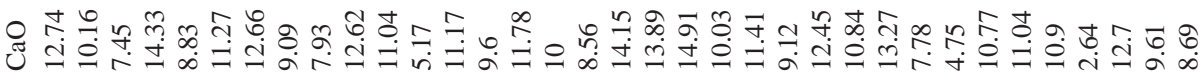

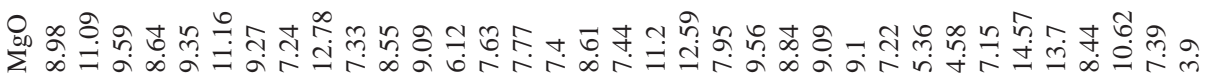

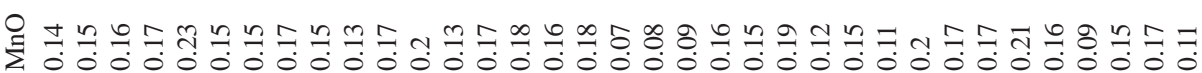
里 กิ $\stackrel{i}{i}$ in

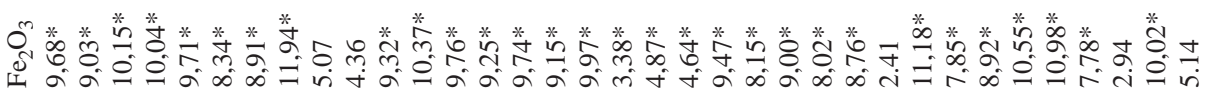

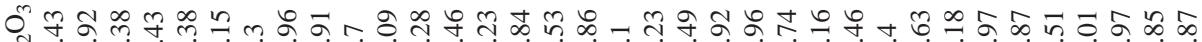

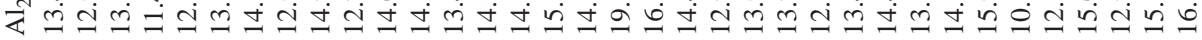

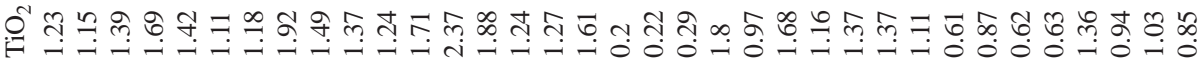
ํำ

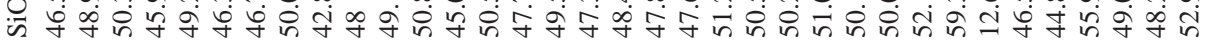

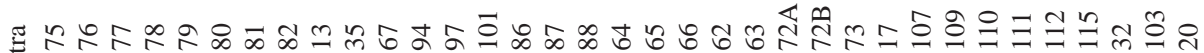

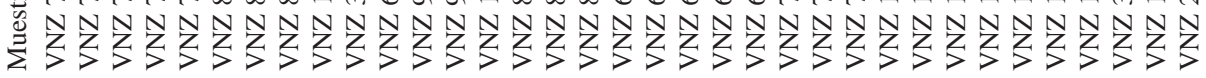
:윰

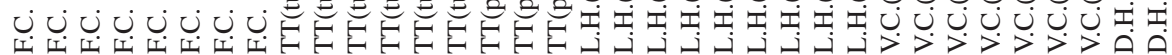




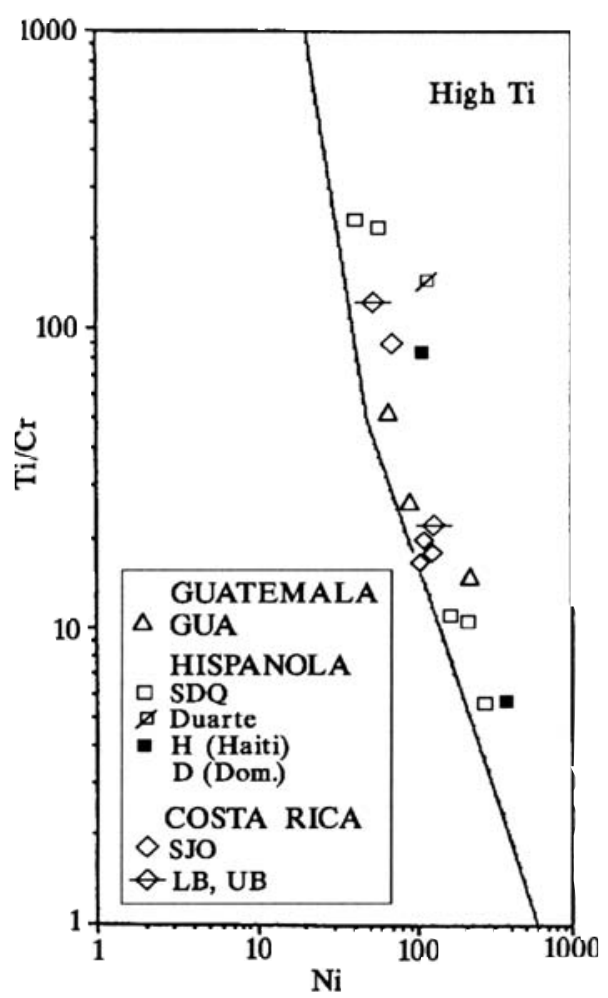

Fig. 6. Diagrama Ti/Cr - Ni (de Beccaluva, 1979) de las muestras de Guatemala, Costa Rica, La Española.

la Unidad Caucagua - El Tinaco, muestran una tendencia más deprimida y relativamente poco enriquecidas respecto a las N-MORB. Los elementos transicionales se ubican en el campo N-MORB; en este caso resulta aparente la afinidad N-MORB del protolito.

2) El complejo peridotítico-gabroide LH de la Unidad Loma de Hierro muestra características de cumulitas, con aumentos en Cr y Ni (cúmulos $\mathrm{Cpx}+\mathrm{Ol}$ ).

3) La Formación Tiara LH (ti) de la Unidad Loma de Hierro presenta características similares a las de la Unidad Franja Costera y de la Formación de Tucutunemo TT(tuc) de la Unidad Caucagua - El Tinaco.

4) Las subunidades de Granofels $\mathrm{VC}(\mathrm{g})$ y de Meta-lavas VC(g) de la Unidad Villa de Cura tienen un fuerte pico positivo del $\mathrm{Ba}$

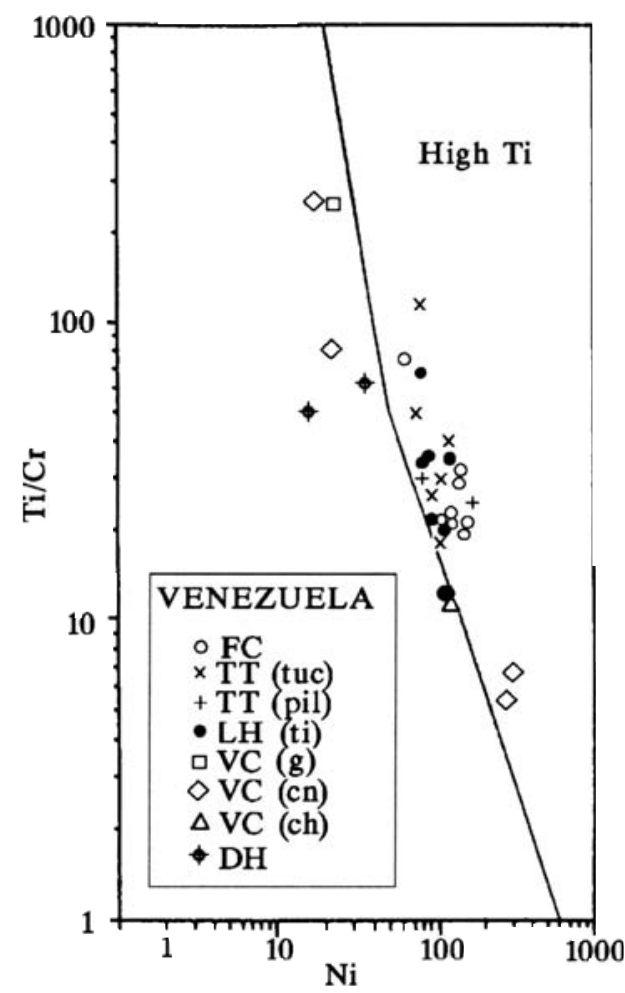

Fig. 7. Diagrama Ti/Cr - Ni (de Beccaluva, 1979) con las muestras de la transversal a la Cordillera de la Costa (Venezuela).

y K y empobrecido en Zr. Por otro lado, los elementos de transición muestran que la Subunidad de Granofels está fraccionada respecto a la Subunidad de Meta-lavas.

5) La Subunidad de meta-tobas VC (ch) de la Unidad Villa de Cura es similar a las de granofels y meta-lavas, excepto por el pico negativo en $\mathrm{Ba}$.

6) La Unidad Dos Hermanas presenta un fuerte pico negativo que puede atribuirse a los procesos de espilitización y/o a la removilización de $\mathrm{K}$ en ambiente metamórfico de bajo grado.

En resumen, los litotipos examinados muestran afinidad MORB. Además, una porción de la Unidad Villa de Cura tiene una afinidad de tipo IAT. 


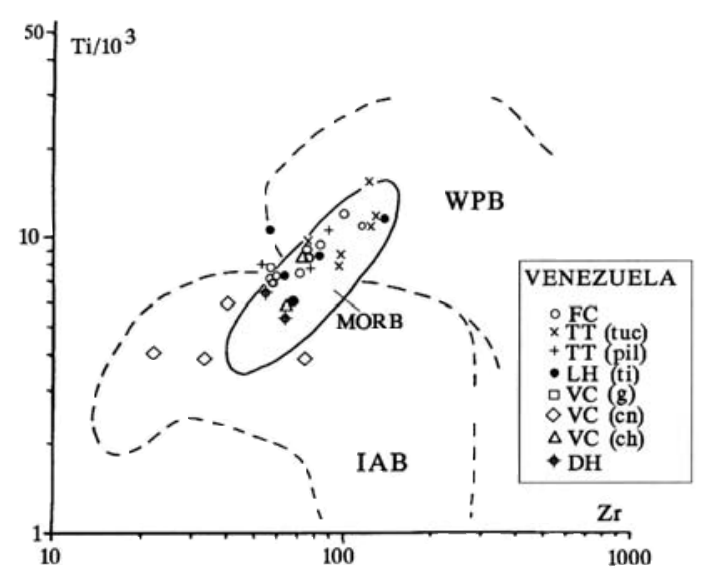

Fig. 8. Diagrama Ti/103 - Zr (de Pearce,1982) con las muestras de la transversal a la Cordillera de la Costa (Venezuela).

\section{RESULTADOS PRELIMINARES Y PROBLEMAS PRINCIPALES}

En esta primera parte de la investigación sobre las unidades ofiolíticas del Caribe, se ha resumido la geometría y la estructura de estos cuerpos rocosos que a menudo afloran en zonas de "sutura" cortical. En el estado actual de las investigaciones, son de importancia los siguientes resultados:

a) Las unidades ofiolíticas del Caribe generalmente se han referido al Jurásico-Cretácico basándose en datos no homogéneos y poco correlacionables (dataciones absolutas K/Ar, estratigrafía de las coberturas, correlaciones). Es indudable que se requieren referencias estratigráficas precisas, para confirmar muchas de las correlaciones que han sido propuestas (Formación El Tambor en Guatemala; Unidades Matapalo y Esperanza en Costa Rica; Complejo Duarte en la Española; Unidades de la Cordillera de la Costa de Venezuela).

b) Las unidades ofiolíticas de los márgenes del Caribe se derivan de la deformación de áreas originalmente oceánicas o de cuencas marginales y a menudo arcos insulares más o menos embrionarios.

Generalmente, las composiciones pueden asociarse a series gabro-basálticas que a veces evolucionan a diferenciados dacíticos (Villa de Cura p.p. y Dos Hermanas de Venezuela). Desde el punto de vista geoquímico, el magmatismo es en buena parte del tipo de alto contenido de $\mathrm{TiO} 2$ referible a MORB; a excepción de algunas unidades de Venezuela (parte de Villa de Cura y Dos Hermanas) que se caracterizan por el bajo contenido de $\mathrm{TiO} 2$, por lo que pueden asociarse a IAT o a PIA. En este último caso, la Unidad Villa de Cura presenta notables variaciones (MORB y IAT) en el ámbito de las subunidades.

c) Las unidades ofiolíticas de los márgenes de la placa del Caribe han sido deformadas y estructuradas en "complejos de subducción", por acreción o "underplating", en el Mesozoico medio-tardío. Cuando están metamorfizadas, la variabilidad de las paragénesis evidencia diferentes modalidades de recristalización en el ámbito de los “complejos", evidenciando la problemática relacionada con la evolución de las subducciones originales y a la no muy clara fenomenología de levantamiento en zonas de obducción.

A la luz de los resultados parciales presentados, podemos dar el siguiente resumen:

La existencia de una o más áreas de corteza oceánica en las unidades aflorantes en el cinturón del Motagua en Guatemala, en la Española, en el Complejo de Santa Elena en Costa Rica y en el de la Cordillera de la Costa (Unidad Loma de Hierro) en Venezuela.

Tales cortezas oceánicas pudieron haber pertenecido a un océano s.s. o a una serie de cuencas marginales. De ser contemporáneas, la edad debe ser del Jurásico Tardío Cretácico Temprano.

La existencia de coberturas volcánicas y volcano-sedimentarias, asociadas a secuencias radiolaríticas y pelítico-carbonáticas más o menos extensas.

Las coberturas volcánicas de todas las unidades (El Tambor en Guatemala, Matapalo y Esperanza p.p. en Costa Rica, Duarte en la Española, Tiara (Unidad Loma de Hierro) y Tucutunemo (Unidad Caucagua-El 
Tinaco), y también las Unidades Franja Costera y Villa de Cura p.p. en Venezuela poseen una afinidad oceánica, representando probablemente la cobertura de la corteza basáltica. La edad podría ser contemporánea y remontarse al Cretácico Temprano, o ligeramente diacrónica en el ámbito de dicho período. Parte del mencionado volcanismo correspondería presumiblemente al llamado "Gran evento basáltico" del Caribe.

- La existencia de "Complejos de Subducción" bajo los arcos insulares embrionarios con zonas de frente de arco (fore arc) próximas a las fosas, con acumulación de secuencias volcano-sedimentarias que evolucionan desde basaltos hasta dacitas, según lo que se evidencia en algunas subunidades de la Unidad de Villa de Cura en Venezuela. La edad debe ser en parte la misma e inmediatamente sucesiva a aquella de las coberturas volcánicas de la unidades de la corteza oceánica.

- La existencia de arcos insulares más o menos evolucionados (PIA) superpuestos a los "Complejos de subducción" con volcanismo andesítico (Unidad Dos Hermanas en Venezuela), que también han alimentado de material volcano-detrítico algunas cuencas adyacentes (Unidades piemontinas, en Venezuela).

Con el fin de evidenciar los principales problemas relativos al origen, significado y evolución de las unidades ofiolíticas se proponen a continuación algunos escenarios geodinámicos:

Basándose en datos paleomagnéticos del océano Atlántico (Ladd, 1976), es probable que las direcciones de deriva de las placas norte y suramericana hayan permitido en el Jurásico-Cretácico, la identificación de una o más áreas oceánicas entre las dos masas continentales principales. Tales áreas, a través del Atlántico embrionario, han podido unirse al complejo Tethys occidental a lo largo del sistema transtensional maghrebino-bético. Muchas de las unidades examinadas poseen características similares a aquellas que afloran en los orógenos perimediterráneos, aunque es fácil intuir que estas características no se han de tratar como únicas. Además, en el Caribe deben aflorar residuos de las terminaciones más occidentales de la Tethys
(Auboin et al., 1977; Auboin \& Tardy, 1980). Estas áreas oceánicas debieron necesariamente haber pasado a aquellas de las placas pacíficas orientales (hoy Nazca y Cocos). Sobre tal problemática no existen todavía elementos discriminativos de importancia.

Siguiendo a Biju-Duval et al.(1978) y Holcombe et al. (1990), la corteza de las cuencas de Colombia y Venezuela sería contemporánea al magmatismo oceánico presente en buena parte de las unidades estudiadas (Cretácico) y parcialmente correspondiente al "Gran evento basáltico" del Caribe. De ello resultaría identificada un área proto-Caribe con características oceánicas generales, de las cuales se conservaría una buena porción, poco o nada deformada, en el substrato de las cuencas mencionadas.

La impredecible eventualidad de que el substrato de las cuencas de Colombia y Venezuela fuese más reciente que el magmatismo de las unidades reconocidas en los márgenes deformados (Jurásico-Cretácico Temprano), indicaría que toda la corteza oceánica protocaribeña ha sido reciclada y/o deformada y que dichas cuencas, asumirían el rol de cuencas marginales o de sedimentos oceánicos conectados al Atlántico, después de las primeras deformaciones de corteza oceánica, o aún al Pacífico, insertándose más tarde en el área caribeña.

Con el inicio de la apertura del Atlántico meridional (Cretácico Temprano) cambiaron los vectores de movimiento de las placas norte y suramericana, con la consiguiente instauración de campos de esfuerzo compresionales en la región caribeña. En la mayoría de los casos, se ha tratado de colisiones producidas en ambientes oceánicos en los cuales las diferentes unidades se han deformado y metamorfizado en situaciones de subducción con formación de prismas de acreción o "underplating". Por encima de tales sistemas se han desarrollado arcos insulares, que en épocas subsiguientes también han sido envueltos en las zonas de colisión, deformándose y metamorfizándose.

Sucesivamente (Cretácico Tardío) se delinean con mayor claridad los márgenes septentrionales y meridionales de la proto-placa del Caribe, como elementos deformados soldados y/o obducidos a las antiguas cortezas continentales de las dos Américas. Desde aquel momento se han también individualizado los márgenes orientales (Antillas Menores) y occidentales (istmo 
centroamericano) de la placa del Caribe. Durante el Cretácico tardío - Paleoceno (Laramidiano) se producen las obducciones de la corteza caribeña 1.s. sobre las placas norte y suramericana y las deformaciones propias de la corteza de aquellas placas, en campos de esfuerzos transpresionales sinestrales al norte y dextrales al sur. No esta claro si este proceso se inició como un frente único compresivo que unía los márgenes septentrional y meridional del Caribe y que se fue torciendo hasta dividirse en dos segmentos, o que los dos márgenes, septentrional (Motagua, Antillas Mayores) y meridional (Cordillera de la Costa), han experimentado una historia cinemática separada.

En el Cenozoico los márgenes caribeños estaban bien definidos, con el desarrollo de arcos volcánicos calcoalcalinos al oriente y al occidente y con la individualización de estructuras de corte discreto en los márgenes septentrional y meridional, que han acentuado la dispersión de los elementos deformados a todo lo largo (ej: 400 $\mathrm{km}$ de transcurrencia sinestral en La Española, desde el Mioceno según Calais et al., 1992)

Lo indicado constituye una visión general de la problemática conectada con las unidades estudiadas. Las diversas soluciones geodinámicas hipotizadas carecen de datos obtenidos con metodologías modernas.

\section{REFERENCIAS}

ANDERSON, T. H. \& SCHMIDT, V.A., 1983: The evolution of Middle America and the Gulf of Mexico-Caribbean Sea region during Mesozoic time. - Geol. Soc. Am. Bull., 94: 941-966.

AUBOIN, J., BLANCHET, R., STEPHAN, J. F. \& TARDY, M., 1977: Tethis (Mésogée) et Atlantique: donnée de la géologie. - C. R. Ac. Sc., 285 (D): 1025-1028.

AUBOIN J. \& TARDY M., 1980: L'Amérique alpine: le domaine Caraibe et ses liaisons avec les Cordillères nord et sur-américaines: introduction. - XXVe Congr. Intern.,v. C-5, Paris 1980.

AZEMA, J., BOURGOIS, J., BAUMGARTNER, P.O., TOURNON, J., DESMET, A. \& AUBOIN, J. 1984 : A tectonic cross-section of the Costa Rican Pacific Littoral as key to the structure of the landward slope of Middle America Trench of Guatemala. - Init. Repts. D. S. D. P.: $831-850$.

BECCALUVA, L., OHNENSTETTER, D. \& OHNENSTETTER, M. 1979: Geochemical discrimination between ocean-floor and island-arc tholeiites - application to some ophiolites. - Can. J. Earth Sci, 16,9: 1874-1882.
BECK, C., 1985: Las napas de Aragua-Cadena Caribe central y la historia mesozoica del margen Sur del Caribe a lo largo del meridiano de Caracas. - Géodynamique des Caraibes. Mascle Ed. Editions Technip: 541-551.

BECK, C., 1986: Caribbean colliding, Andean drifting and the Mesozoic-Cenozoic geodynamic evolution of the Caribbean. - Soc. Ven. Geol., Mem. VI Congreso Geológico Venezolano, 10: 6575-6614.

BELLIZZIA, A., 1986: Sistema Montañoso del Caribe, una cordillera alóctona en la parte Norte de América del Sur. - Soc. Ven. Geol., Mem. VI Congreso Geológico Venezolano, 10: 6657-6836

BELLIZZIA, A. \& DENGO G., 1990: The Caribbean mountain system, northern South America; a summary. Geol. Soc. Am. Vol. H. The Caribbean Region: 167176.

BIJU-DUVAL, B., MASCLE, A., MONTADERT, L. \& WANNESON, J., 1978: Seismic investigations in the Colombia, Venezuela, and Grenada Basins and on the Barbados Ridge for future IPOD drilling. - Geologie en Mijnbouw, 57,2: 99-104.

CALAIS, E.; MERCIER DE LEPINAY, B. M.; SAINTMARC, P., BUTTERLIN J. \& SCHAAF, A., 1992: La limite de plaques décrochante nord caraibe en Hispaniola: evolution paleogeographique et structurale cénozoique. - Bull. Soc Geol. France, 163,3.

CARNEMOLla, S., CUSimANo, G., DI NATALE, R., GIUNTA, G., 1990: La Cuenca hidrográfica del Rio Tuy (Venezuela): Introducción a la geología del Sistema Montañoso del Caribe. - 143 págs., Quad. IILAROMA, Serie Scienza 2.

CASE, J. E. \& HOLCOMBE, T. L., 1980: Geologic-tectonic map of the Caribbean. Scale 1:2500000. - U. S. Geol. Surv., Miscell. Invest. Ser., Map I/1100.

CASE, J.E., MCDONALD, W. D. \& FOX, P. J., 1990: Caribbean crustal provinces; seismic and gravity evidence. Geol. Soc. Am. Vol. H., The Caribbean Region: 15-36.

DENGO, G., 1972: Review of Caribbean serpentinites and their tectonic implications. - Geol. Soc. America Memoir, 132: 303-312.

DENGO, G., 1985: Mid America: tectonic setting for the Pacific margin from Southern Mexico to North western Colombia. - En: Nairn A.E.M., Stehli F.G.\& Uyeda S. (eds): The Ocean Basin and Margins, 7: 123-180.

DENGO, G \& CASE, J. (eds.), 1990: The Caribbean Region. The Geology of North America. - 528 págs., Geol. Soc. Am. Vol. H.

DONNELLY, T. W., BEETS, D., CARR, M.J., JACKSON, T., KLAVER, G., LEWIS, J., MAURY, R., SCHELLEKENS, H., SMITH, A.L., WADGE, G. \& WESTER- 
CAMP, D., 1990: History and tectonic setting of Caribbean magmatism. - Geol. Soc. Am. Vol. H. The Caribbean Region: 339-374.

DONNELLY, T., HORNE, G. S., FINCH, R. C. \& LOPEZRAMOS, E., 1990: Northern Central America; The Maya and Chortis blocks. - Geol. Soc. Am. Vol. H., The Caribbean Region: 37-76.

ERNST, W.G., 1975: Subduction zone metamorfism. Benchmark Papers in Geology, W.G.Ernst Ed. v. 19, Dowden, Hutchinson \& Ross, Inc.

ESCALANTE, G. 1990: The Geology of southern Central America and western Colombia. - Geol. Soc. Am. Vol. H., The Caribbean Region: 201-230.

FINCH, R. C. \& DENGO, G., 1990: NOAM-CARIB Plate Boundary in Guatemala: A Cretaceous Suture Zone Reactivated as a Neogene Trasform Fault. - Geol. Soc. Am. 1990 Annual Meeting.

GRATEROL, V. \& FONSECA, A., 1978: Gravimetría en Venezuela. - Bol. de Geol., M.M.H. v. XIII, 24, Caracas.

GURSKY, M., 1988: Análisis tectónico de la Península de Nicoya (Costa Rica) y su significado para el desarrollo estructural-geodinámico de América Central Meridional. - Rev. Geol. América Central, 8: 19-76.

HOLCOMBE, T. L., LADD, J. W., WESTBROOK, G., EDGAR, N. T. \& BOWLAND, C. L., 1990: Caribbean marine geology; ridges and basins of the plate interior. - Geol. Soc. Am. Vol. H., The Caribbean Region: 231260

KUIJPERS, E. P. 1980: The geologic history of the Nicoya ophiolite complex, Costa Rica, and its geotectonic significance. - Tectonophysics, 68: 233-255.

LADD, J. W., 1976: Relative motion of South America with respect to North America and Caribbean tectonics. G.S.A. Bull., 87,7: 969-976.

LEWIS, J. F., DRAPER, G. \& BURGI, D., 1983: Geochemistry and petrology of high-magnesium metabasalts of the Duarte complex, Dominicanan Republic. - 10th Caribbean Geological Conference, Cartagena. Colombia . Abstract.

LEWIS, J. F. \& DRAPER, G., 1990: Geology and tectonic evolution of the northern Caribbean margin. - Geol. Soc. Am. Vol. H., The Caribbean Region: 177-140.

MCDONALD, W.D., 1990: Survey of Caribbean paleomagnetism. - Geol. Soc. Am. Vol. H., The Caribbean Region: 393-404.

MASCLE, A. Ed., 1985: Géodynamique des Caraibes. Editions Technip.

MAURY, R.C., WESTBROOK, G.K., BAKER, P.E., BOUYSSE, P. \& WESTERCAMP, D., 1990: Geology of the Lesser Antilles. - Geol. Soc. Am. Vol. H., The Caribbean Region: 141-166.

MESCHEDE, M. FRISCH, W.\& SICK, M. 1988: Interpretación geodinámica de los Complejos Ofiolíticos de Costa Rica. - Rev. Geol. América. Central, 8: 1-17.

MORRIS, A. E. L., TANER, I., MEYERHOFF, H. A. \& MEYERHOFF, A. A., 1990: Tectonic evolution of the Caribbean region; Alternative hypothesis. - Geol. Soc. Am. Vol. H., The Caribbean Region: 433-458.

NAVARRO, E., 1983: Petrología y petrogénesis de las rocas metavolcánicas del Grupo Villa de Cura. - Geos, (28): $170-317$

NAVARRO, E., OSTOS, M. \& YORIS, F., 1988: Revisión y redefinición de unidades litoestratigráficas y síntesis de un modelo tectónico para la evolución de la parte nortecentral de Venezuela durante el Jurásico medio-Paleógeno. - Acta Científica Venezolana Geología, vol. 39.

NAVARRO, E., 1989: Antiguas y nuevas teorías sobre el origen y emplazamiento de la faja de Villa de Cura. Soc. Ven. Geol. - Congreso Geológico Venezolano 1989.

OSTOS, M., 1992: Evolución tectónica del margen sur central del Caribe, basado en datos geoquímicos.- Geos, 30[1990]: 1-294.

OSTOS, M. \& NAVARRO, E., 1986: Faja de Villa de Cura. Realmente un complejo de arco de isla alóctono? - Soc. Ven. Geol. Mem. VI Congreso Geológico Venezolano.

PEARCE, J. A., 1982: Trace element characteristics from destructive plate boundaries. - En: Thorpe, R.S. (ed.): Andesites: 525-548,.Wiley \& Sons, New York.

PINDELL, J. L.\& BARRETT, S. F., 1990: Geological evolution of the Caribbean region; a plate-tectonic perspective. Geol. Soc. Am. Vol. H., The Caribbean Region: 405-432.

ROSS, M. I. \& SCOTESE, C. R., 1988: A hierarchical tectonic model of the Gulf of Mexico and Caribbean region. - Tectonophysics, 155: 139-168.

STEPHAN, J. F., 1985: Andes et chaine Caraibe sur la transversale de Barquisimeto (Venezuela). Evolution Géodinamique. - Geodynamique des Caraibes, Paris. Editions Technip: 505-529.

STEPHAN, J. F., BLANCHET, R. \& MERCIER DE LEPINAY, B., 1986: Northern and Southern Caribbean Festoons (Panama, Colombia, Venezuela, Hispaniola, Puerto Rico) interpreted as subductions induced by the East West shortening of the Pericaribbean continental frame. - En: Wezel F.C. (ed.): The Origen of Arcs, Development in Geotectonics, 21, Elsevier.

STEPHAN, J. F., MERCIER DE LEPINAY, B., CALAIS, E., TARDY, M., BECK, C., CARFANTAN J. C., OLIVET, J. L.,VILA, J. M., BOUYSSE, P., MAUFFRET, A., BOURGOIS, J., THERY, J. M., TOURNON, J., 
BLANCHET, R. \& DERCOURT, J., 1990: Paleogeodynamic maps of the Caribbean: 14 steps from Lias to Present. - Bull. Soc. Géol. France, 8, VI,6.

URBANI, F. \& OSTOS, M., 1989: El Complejo Avila, Cordillera de la Costa, Venezuela. - Geos, 29: 205-217.
URBANI, F., CHIRINOS, A. \& MARQUINA, F. 1991: Geología del área de Guatopo-El Guapo, estados Miranda y Guárico. - Rev. Fac. Ingeniería, (UCV, Caracas), 5(1): 96-126. 